\footnotetext{
${ }^{1}$ Institute of Meteorology and Geophysics, University of Innsbruck, Innsbruck, Austria

${ }^{2}$ Institut für Physik der Atmosphäre, Deutsches Zentrum für Luft- und Raumfahrt (DLR), Oberpfaffenhofen, Germany

${ }^{3}$ Institute of Ion Physics and Applied Physics, University of Innsbruck, Innsbruck, Austria

${ }^{4}$ MetAir AG, Switzerland
}

\title{
Spatial distribution of aerosols in the Inn Valley atmosphere during wintertime
}

\author{
F. Harnisch ${ }^{1}$, A. Gohm ${ }^{1}$, A. Fix ${ }^{2}$, R. Schnitzhofer ${ }^{3}$, A. Hansel ${ }^{3}$, B. Neininger $^{4}$ \\ With 7 Figures
}

Received 28 September 2007; Accepted 14 March 2008

Published online 22 October 2008 (C) Springer-Verlag 2008

\begin{abstract}
Summary
This study analyzes the structure of the wintertime boundary layer in an Alpine valley (Inn Valley, Austria) for a case of high air pollution. We present airborne aerosol observations collected with particle counters and a backscatter lidar. The effect of upslope winds on the spatial distribution of pollutants is investigated. An asymmetry in the aerosol distribution is observed in the cross-valley direction which presumably is related to differences in orientation and albedo of the two valley slopes. A one-sided thermal circulation, which develops above the sun-exposed slope, is most likely responsible for the observed redistribution of aerosols during daytime. Elevated aerosol layers form at the height of shallow inversion layers. Despite this vertical transport of pollutants by slope winds, no effective vertical venting of the polluted air mass into the free atmosphere can be achieved.
\end{abstract}

\section{Introduction}

With the increase of heavy goods vehicle (HGV) traffic over the last years, air pollution has become a hotly debated subject. HGV traffic along

Correspondence: Alexander Gohm, Institute of Meteorology and Geophysics, University of Innsbruck, Innrain 52, 6020 Innsbruck, Austria (E-mail: alexander.gohm@uibk.ac.at) major Alpine transport routes, such as the autobahn through the Inn Valley and over the Brenner Pass, has strongly contributed to the air pollution problem in these densely populated areas (Beauchamp et al. 2004). For the period between 2002 and 2012 an increase in total traffic volume of more than 35 percent has been predicted (Thudium 2003). Coupled with this increase of traffic and air pollution the impact on human health - for example the risk of lung cancer mortality (Pope et al. 2002) - increases as well. The vertical structure (stability) of the atmospheric boundary layer has a major impact on the distribution of air pollutants (see e.g., Hanna and Strimaitis 1990; Chazette et al. 2005). Particularly in wintertime, Alpine valleys are favored locations for high air pollution due to the formation of cold pools characterized by strong surface inversions which frequently decouple the valley atmosphere from the background synoptic flow. As long as convective mixing is not dominant (e.g., during nighttime), valley walls limit plume spread and the volume of air through which the plume can be dispersed (Whiteman 2000). These effects reduce the dispersion of pollutants and 
the exchange of air masses. For a given emission, the morning peaks of $\mathrm{NO}_{\mathrm{x}}$ concentration can be up to nine times higher in the Inn Valley than over flat terrain (Wotawa et al. 2000). Also local circulations and wind systems affect the aerosol distribution. One of the few dispersion processes
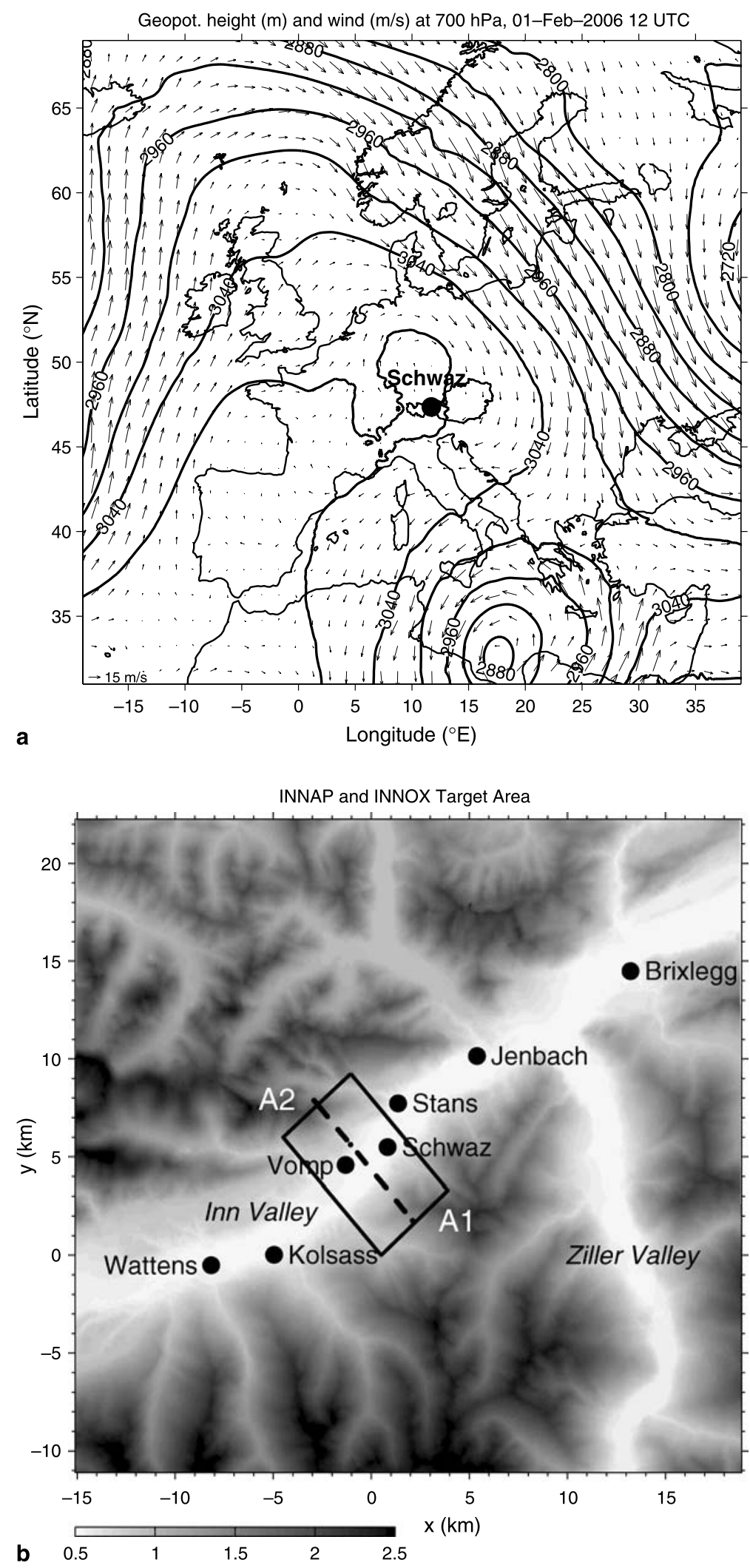

Fig. 1. (a) ECMWF Analysis of geopotential height $(\mathrm{m})$ and wind speed $\left(\mathrm{m} \mathrm{s}^{-1}\right)$ at $700 \mathrm{hPa}$ at 12 UTC 01 February 2006. (b) Close-up of the Inn Valley. The town of Schwaz is marked by a circle in (a) and (b). The dashed line (A1A2) in (b) represents the flight track of the DLR Cessna Grand Caravan. A box in (b) surrounds the area covered by the MetAir aircraft 


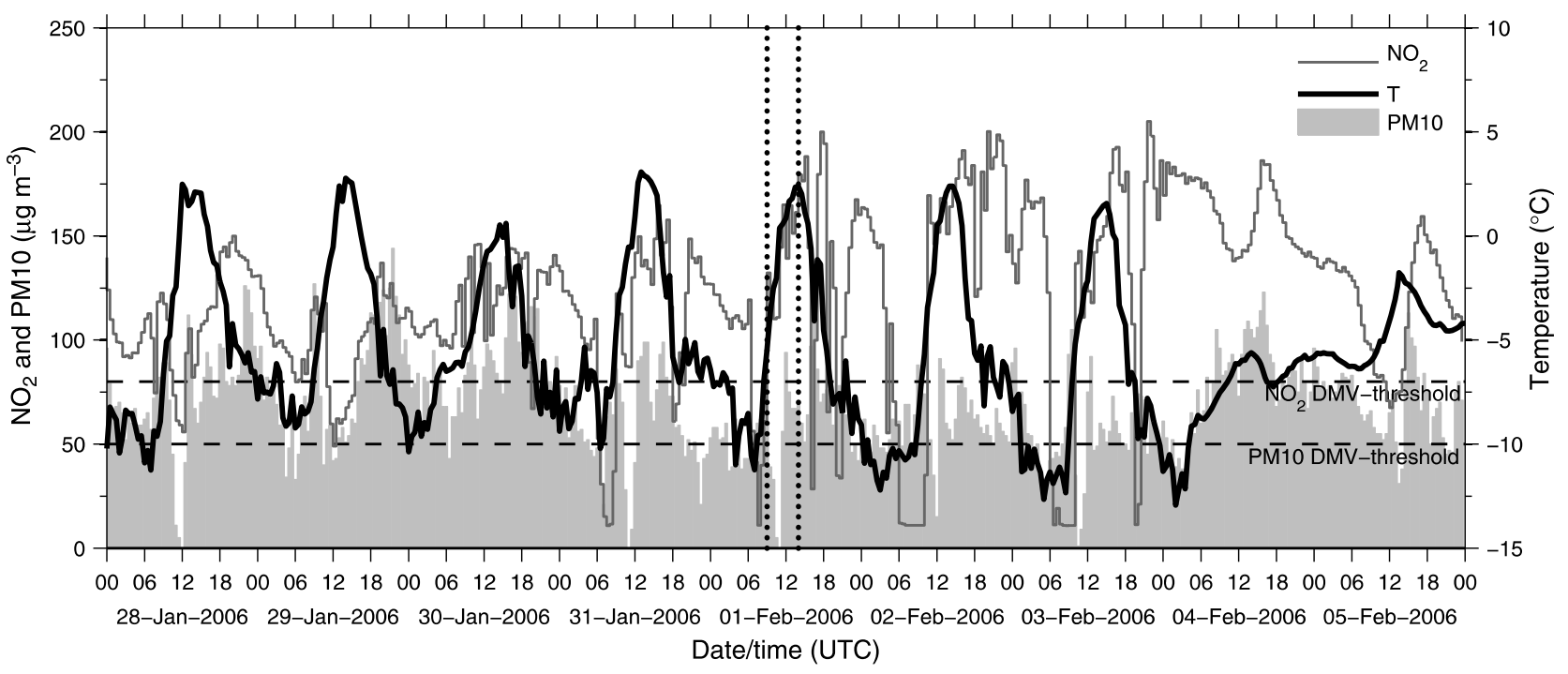

Fig. 2. Time series of PM10 $\left(\mu \mathrm{g} \mathrm{m}^{-3}\right), \mathrm{NO}_{2}\left(\mu \mathrm{g} \mathrm{m}^{-3}\right)$ and temperature $\left({ }^{\circ} \mathrm{C}\right)$ at the ALPNAP station Schwaz (c.f. Fig. 1) between 28 January and 05 February 2006. The vertical dotted lines indicate the times of the morning and afternoon flight, respectively. The horizontal dashed lines represent the daily mean value (DMV) thresholds of $50 \mu \mathrm{g} \mathrm{m}^{-3}$ for PM10 and of $80 \mu \mathrm{g} \mathrm{m}^{-3}$ for $\mathrm{NO}_{2}$, respectively

for polluted air masses during daytime are thermally induced upslope flows, which transport pollutants away from the sources, mostly located at the valley bottom, up to higher levels (Bader and Whiteman 1989). Emeis et al. (2007) showed that multiple thermal layering is a frequently observed feature of the wintertime atmosphere in the Inn Valley. Despite the destruction of the surface inversion during the day, one or more pronounced inversion layers may still exist below crest level. These elevated inversions reduce mass flux in the slope wind layer and consequently hinder an effective air mass exchange (Vergeiner and Dreiseitl 1987).

Three-dimensional measurements, e.g., by airborne observations, have proved useful to identify the mechanisms of aerosol transport and of the formation of aerosol layers that form under certain conditions over complex terrain. Wakimoto and McElroy (1986) found that elevated aerosol layers are formed over Los Angeles in summer by the combined effect of orography (forced and free convection) and convective mixing. Chazette et al. (2005) showed that in the snow-covered Chamonix valley pollutants were mainly trapped close to the ground, whereas convective mixing and the formation of elevated layers were observed in the Maurienne valley with a bottom surface mostly free of snow. A strong coupling between different wind systems and the transport of aerosols and trace gases, in particular ozone, has been proved in the Mesolcina valley during the VOTALP campaign (e.g., Carnuth and Trickl 2000; Furger et al. 2000; Prévôt et al. 2000). The above described studies all show that the aerosol distribution is governed by several factors, such as terrain properties, seasons and prevailing winds.

The goal of this study is to examine the spatial distribution of aerosols in the Inn Valley during wintertime and the influence of local winds on pollutant transport and dispersion. For this purpose two research aircraft conducted several missions in winter 2006 during the field campaign of the research projects INNAP ${ }^{1}$ and INNOX ${ }^{2}$, respectively. These projects were embedded into the major research project ALPNAP $^{3}$ (Heimann et al. 2007) which covered measurements in various Alpine valleys. The aircraft carried an aerosol backscatter lidar and various instruments for in-situ observations. First results are presented in Emeis et al. (2007), Schnitzhofer et al. (2007), and Gohm et al. (2006). An overview of the target area in the Inn Valley near the town of

\footnotetext{
${ }^{1}$ Boundary layer structure in the Inn Valley during high air pollution

${ }^{2} \mathrm{NO}_{\mathrm{x}}$-structure in the Inn Valley during high air pollution

${ }^{3}$ Monitoring and minimisation of traffic-induced noise and air pollution along major Alpine transport routes
} 
Schwaz is depicted in Fig. 1. Aircraft measurements were performed on several days between 16 January 2006 and 02 February 2006. The following sections present results from a specific case study of the 01 February 2006. This day, being part of a period of six consecutive highpressure days, was characterized by few clouds, weak synoptic winds and high concentrations of pollutants in the valley atmosphere (cf. Fig. 2). Two different flights, one conducted in the morning and one in the afternoon, allow to study the diurnal evolution of the boundary layer and the impact on the distribution of pollutants. Section 2 introduces the instrumentation of the research aircraft and the dataset analyzed herein. Section 3 describes the synoptic and mesoscale situation in the Inn Valley and presents the measurements and results. Conclusions are drawn in Sect. 4.

\section{Description of the dataset}

The MetAir Dimona is a small research aircraft which carries instruments for in-situ observations of meteorological and air chemistry parameters (Neininger et al. 2001). Particle measurements and a subset of meteorological parameters are analyzed in the present study. The MetOne is a laser-based particle counter which outputs the total number of particles with a diameter greater than $0.3 \mu \mathrm{m}$. The instrument has a high temporal resolution of $1 \mathrm{~Hz}$, however, is not optimized for very high concentrations. The Grimm sensor is a spectrometer, which measures particle concentrations for 15 size bins between 0.3 and $20 \mu \mathrm{m}$. It has to be operated at a much lower temporal resolution (e.g., at a 1-min sampling interval) in order to improve distribution statistics especially for big particles. In this study Grimm data is used in order to remove the coincidence count error in the MetOne dataset which occurred for concentrations typically greater than 100 particles per ml. This new corrected MetOne parameter "fit03" is discussed in the subsequent sections and describes the total number of particles greater than $0.3 \mu \mathrm{m}$. Further, measurements of potential temperature, wind speed and wind direction within a 2-km wide subdomain of the flight path, covering the flat part of the valley, are used for creating pseudo-vertical profiles. These profiles complement the available radiosoundings (see below). The MetAir Dimona flight pattern con- sists of vertically staggered quasi-horizontal legs which are approximately aligned on a vertical transect across the Inn Valley near the town of Schwaz (see Fig. 1b). Due to the narrow valley, legs close to the ground had to be flown as loops instead of straight lines.

The TropOLEX lidar (Meister et al. 2003) developed at the German Aerospace Center (DLR) was operated in a nadir-pointing mode on board the DLR Cessna Grand Caravan aircraft. In this study we present aerosol backscatter intensity data at a wavelength of $1064 \mathrm{~nm}$. The horizontal and vertical resolution of the lidar dataset is $\sim 40 \mathrm{~m}$ and $15 \mathrm{~m}$, respectively. A major contribution to the backscatter signal stems from particulate matter emitted by anthropogenic sources, such as traffic as well as industrial and domestic burning. The measured backscatter intensity is proportional to the number and size of aerosols in each resolved volume and is displayed in arbitrary units. A regular flight pattern of the DLR Cessna consists of several repeated along and across-valley transects. In the present study we restrict our analysis to a selected cross-section, which is located close to the MetAir Dimona transect, in order to compare lidar and in-situ measurements (cf. Fig. 1b).

During aircraft missions several radiosoundings were launched from the airport of Innsbruck, located in the Inn Valley approximately $30 \mathrm{~km}$ west of the target area. Besides the operational ascent at approx. 03UTC, additional ascents were carried out during aircraft operations. Further, meteorological and air quality measurements, conducted at the station Schwaz within the framework of the project ALPNAP, are used for this study.

\section{Results}

\subsection{Synoptic and mesoscale overview}

January and February 2006 were characterized by monthly mean surface temperatures below the long-term average and a closed snow cover in major parts of the Inn Valley. During these two months several synoptically undisturbed periods occurred which were associated with periods of high air pollution. In the present study we focus on the 01 February 2006. On this day, morning as well as afternoon flights have been conducted 

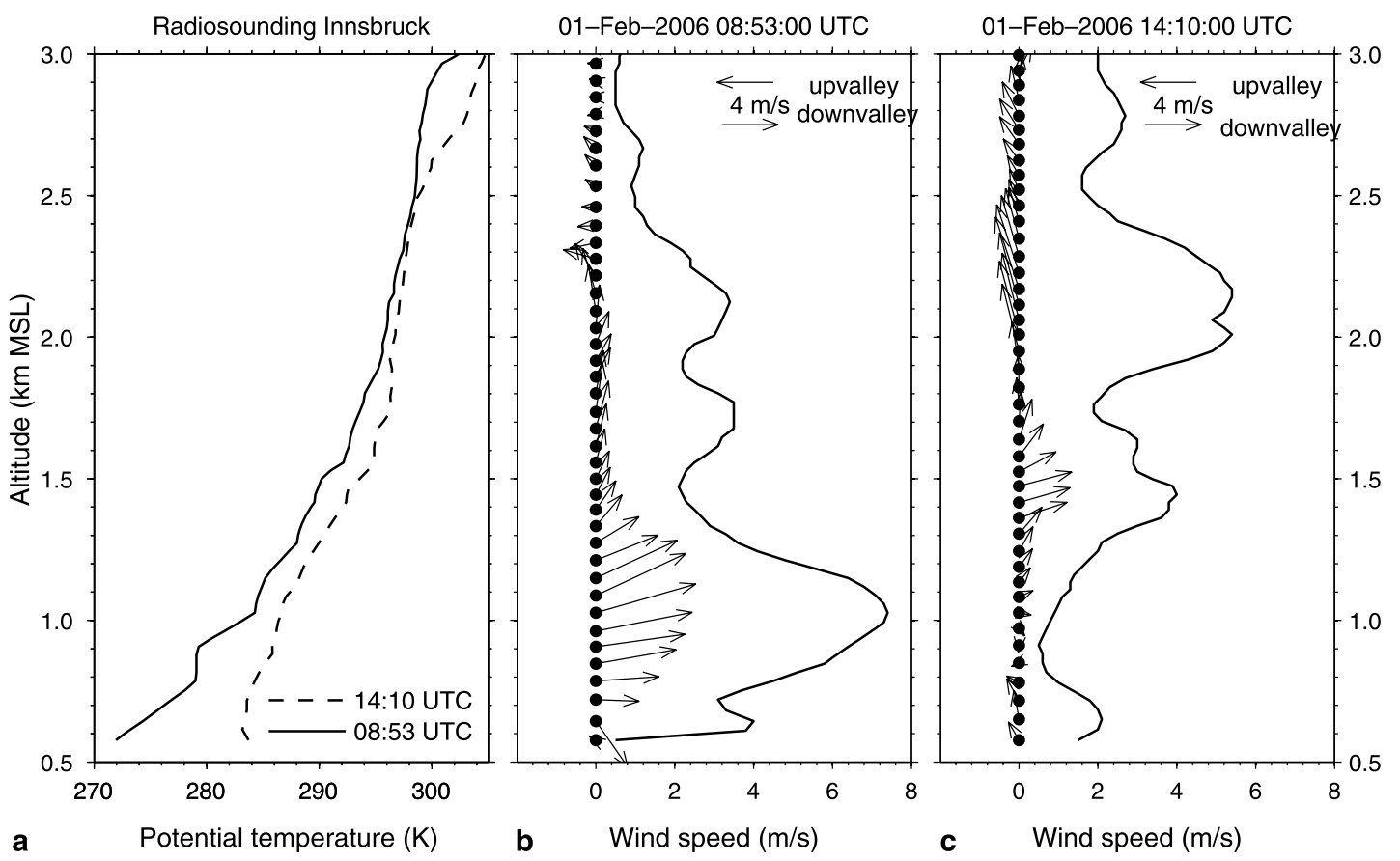

Fig. 3. Radiosoundings at the Innsbruck Airport on 01 February 2006: (a) Potential temperature (K) at $\sim 09$ UTC (solid) and $\sim 14$ UTC (dashed). Horizontal wind speed $\left(\mathrm{m} \mathrm{s}^{-1}\right.$ ) and wind direction (wind arrows) at (b) $\sim 09$ UTC, and $(\mathbf{c}) \sim 14$ UTC

with both aircraft. Figure 2 presents the temperature, $\mathrm{NO}_{2}$ and PM10 records from the station Schwaz (cf. Fig. 1) between 28 January and 05 February 2006. The 01 February is characterized by high values of $\mathrm{NO}_{2}$ with a daily mean concentration of $120 \mu \mathrm{g} \mathrm{m}^{-3}$. The concentration of fine particles, in particular PM10, has a daily mean value of $58 \mu \mathrm{g} \mathrm{m}^{-3}$ and violates the threshold of the European air quality directive of $50 \mu \mathrm{g} \mathrm{m}^{-3}$ (see e.g., Heimann et al. 2007). The PM10 concentration follows a diurnal cycle, with high concentrations during the morning, a minimum shortly before noon, and again high concentrations in the afternoon and evening. This diurnal pattern could also be observed during other days of the shown period.

The synoptic situation in the Alpine region was characterized by a high pressure system with its center over the south of Germany (cf. Fig. 1a). Solar insolation was nearly undisturbed by clouds, except from some thin cirrus. During daytime generally weak southerly winds, with wind speeds between 2 and $6 \mathrm{~m} \mathrm{~s}^{-1}$, were observed near crest level. The analysis of the radiosounding conducted at the airport of Innsbruck at 0853 UTC (Fig. 3a, b) indicates a stable stratification with a strong surface inversion and an increase of potential temperature of $20 \mathrm{~K}$ within the lowest kilometer above ground. A jet-like structure in the vertical profile of wind speed, with a maximum of $8 \mathrm{~m} \mathrm{~s}^{-1}$ near $1000 \mathrm{~m}$ MSL (Mean Sea Level), reveals the nocturnal down-valley flow. The afternoon sounding at 1410 UTC (Fig. 3a, c) shows that daytime heating of the boundary layer has reduced the average vertical gradient of potential temperature in the lowest kilometer above ground to $9 \mathrm{~K} \mathrm{~km}^{-1}$. Nevertheless, some elevated inversion layers are still present. Basically a 500-m deep layer above the surface is affected by this heating. This layer exhibits weak winds, which change directions from southeast over east to west with increasing height. Above this layer but well below crest height westerly down-valley winds prevail. Pseudo-vertical profiles (Fig. 4) constructed from MetAir data depict a similar structure. These profiles are extended to the surface with observations from the automatic weather station Schwaz. In the morning, the stable stratification of the lower atmosphere with a pronounced surface inversion is clearly evident. The wind profile, exhibiting a jet-like structure of the down-valley flow, fits well with the radiosounding. In the afternoon, at least two elevated inversion layers can be identified at $\sim 900 \mathrm{~m} \mathrm{MSL}$ 

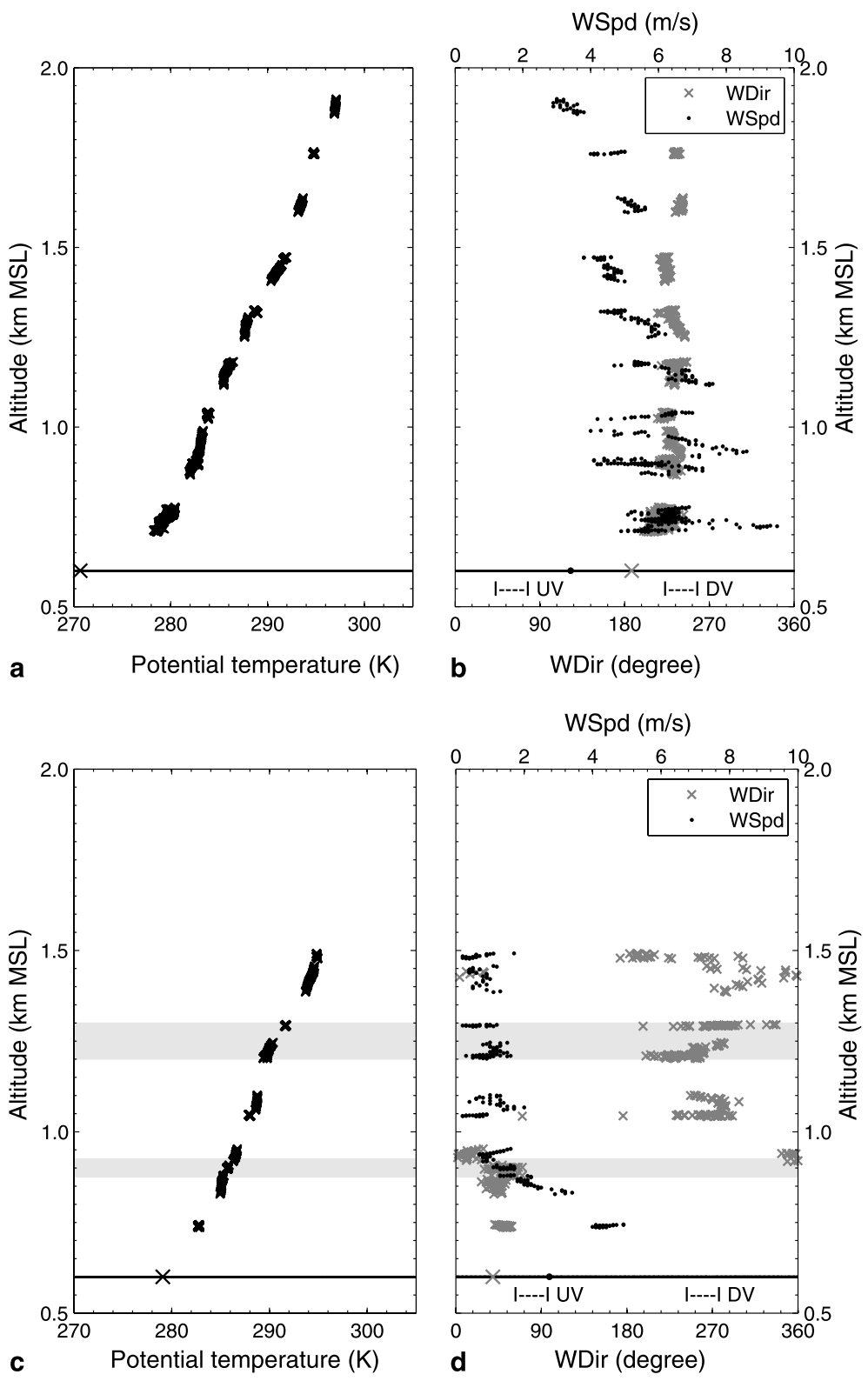

Fig. 4. Pseudo-vertical profiles constructed from MetAir data for (a) and (b) the morning flight between 0856 and 1010 UTC and (c) and (d) the afternoon flight between 1340 and 1412 UTC on 01 February 2006: Vertical profiles of (a) and (c) potential temperature $(\mathrm{K})$ and $(\mathbf{b})$ and (d) wind speed $\left(\mathrm{m} \mathrm{s}^{-1}\right)$ and wind direction (degree). Gray bars in (c) and (d) represent shallow inversions. The labels 'UV' and 'DV' denote the up-valley and down-valley wind sector, respectively. The lowest data points are taken from surface measurements at the station Schwaz

and $\sim 1250 \mathrm{~m}$ MSL (marked with gray bars in Fig. 4c, d). Further, it also becomes evident that a $400-\mathrm{m}$ thick layer near the surface exhibits up-valley winds with wind speeds smaller than $4 \mathrm{~m} \mathrm{~s}^{-1}$. Above this layer winds are very weak from westerly and northerly directions. Surface wind speeds during the day are generally below $3 \mathrm{~m} \mathrm{~s}^{-1}$. Automatic weather stations along the Inn Valley (not shown) support the existence of a thermally induced wind system and indicate a transition from down-valley to up-valley flow at $\sim 12$ UTC. These up-valley winds were quite rare in winter 2006, but have also been found on other days during the field campaign.

\subsection{Boundary layer structure in the morning}

Figure 5 illustrates the aerosol concentration and backscatter intensity observed during the morning flight between 09 and 10 UTC. Shown is a vertical transect across the valley from southeast (left side) to northwest (right side of Fig. 5). Since the flight pattern of the MetAir Dimona consists of vertically staggered quasi-horizontal loops, each leg covers slightly different terrain as indicated in Figs. 5a and 6a. The gray shaded area in these figures represents the maximum and the minimum height of the topography and the solid line the mean height within a 6-km wide 

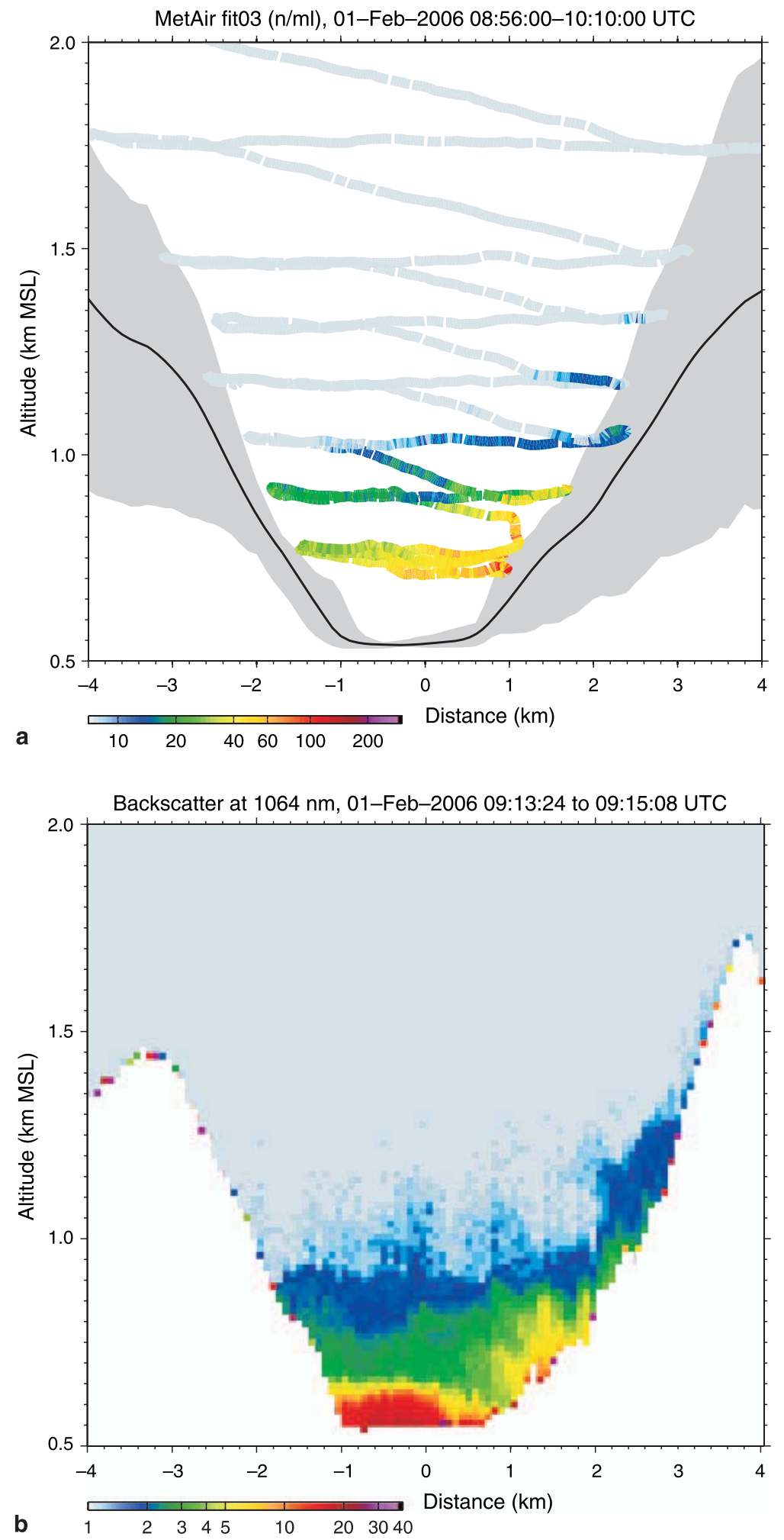

Fig. 5. Vertical transect across the Inn Valley of (a) aerosol concentration for particles greater than $0.3 \mu \mathrm{m}$ (particle number per ml; MetAir Dimona) and (b) aerosol backscatter intensity (arbitrary units; DLR TropOLEX lidar). The color scale is logarithmic in (a) and (b). The mean topography in (a) is shown as solid line, and the limits of the topography as gray shaded area. Topography in (b) is white. Figures are for the morning flight at $\sim 09$ UTC on 01 February 2006. See text for further explanation

box shown in Fig. 1b. This box surrounds the "footprint" of the MetAir flight track. It took around $60 \mathrm{~min}$ to collect the data for a single vertical transect (see A1A2 in Fig. 1b). The DLR Cessna, however, collected data of a whole vertical transect along a single straight flight leg within a few minutes. Hence, some of the discrepancies between in-situ observations and lidar measurements are related to slightly different sample volumes and times of the two instruments. 
In the morning, the horizontal distribution of aerosols is nearly homogeneous (Fig. 5). The vertical aerosol structure is essentially characterized by three layers. In agreement with the strong surface inversion detected by the radiosounding
(Fig. 3a), highest aerosol backscatter intensities are found in an approximately 100-m deep layer near the ground. Due to control and safety restrictions on flight operations the MetAir aircraft could not probe the atmosphere below $\sim 150 \mathrm{~m}$
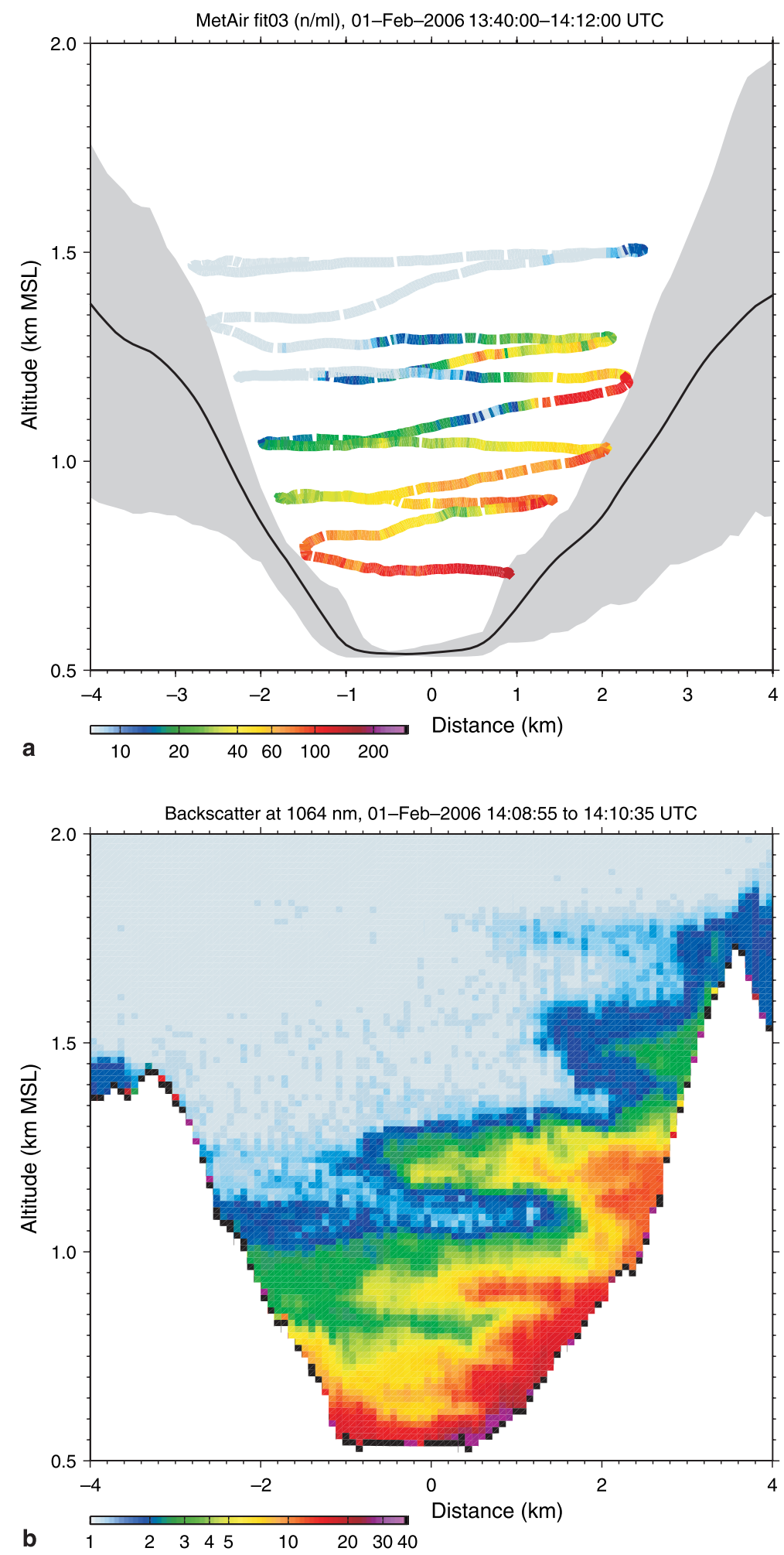

Fig. 6. As in Fig. 5, but for the afternoon flight at $\sim 14$ UTC on 01 February 2006 
AGL (Above Ground Level). However, tethered balloon data (not shown) support this view of a highly polluted layer close to the surface (Schnitzhofer et al. 2007). In a second, 200-m deep layer backscatter intensities are lower by factor of 4. In this layer, aerosol concentrations measured by the MetAir Dimona aircraft are between 20 and 70 particles per $\mathrm{ml}$. In a third layer, above $\sim 900 \mathrm{~m} \mathrm{MSL}$, the valley atmosphere is very clean. There, the measured aerosol concentrations drop to values below 10 particles per $\mathrm{ml}$. A first sign of an asymmetric structure of the spatial aerosol distribution can be identified from slightly higher backscatter intensities and aerosol concentrations above the south-eastward facing sun-exposed slope (right hand side of Fig. 5a, b). This feature is presumably caused by upward aerosol transport within the developing slope wind layer on the sun-exposed valley side. Yet, the shaded side of the valley remains essentially unaffected by this developing slope wind regime. In this context it is noteworthy that differences in the snow coverage between the two valley sides existed (see next section).

\subsection{Diurnal evolution of the boundary layer structure}

Until the afternoon the structure of the boundary layer has changed significantly (Fig. 6). The dominant feature at $\sim 14$ UTC is an asymmetric aerosol distribution with strong differences in aerosol concentrations between the two valley sides. Other vertical transects of backscatter intensity (not shown) conducted between the towns of Kolsass and Jenbach (cf. Fig. 1b) are also characterized by this asymmetric structure. Therefore Fig. $6 \mathrm{~b}$ may be seen as representative for a larger part of the Inn Valley.

It is most likely that thermally induced upslope winds on the south-exposed slope (right side of Fig. 6) are responsible for the transport of aerosols up to higher elevations. In contrast, only weak vertical transport can be found on the opposite (north-exposed) slope, which is most likely the result of missing upslope winds. We hypothesize that the different slope flow behavior on the two valley sides is caused by the different orientation and albedo of the two slopes. The difference in the albedo is a result of nearly snow-free tree tops at the south-ex- posed slope and stronger snow coverage on the opposite slope. Unfortunately, no wind measurements are available, which could resolve the thin ( decameter) slope wind layer and would give a direct proof of this circulation pattern. The formation of a relatively thick ( $\sim$ hectometer) layer with high aerosol backscatter intensities along the sun-exposed slope is attributed to continuous detrainment of polluted air from the thin slope wind layer into the ambient valley atmosphere. A similar event characterized by an asymmetric aerosol distribution, presumably induced by a thermal circulation, has been discussed by Gohm et al. (2006). Also during the VOTALP experiment in the Swiss Mesolcina valley an asymmetric structure of the aerosol distribution across the valley was observed by a lidar system and partly attributed to different orientation of the two valley slopes towards the sun (Carnuth and Trickl 2000). An asymmetric flow structure with a secondary circulation was observed in the Riviera Valley, Switzerland, during summer (Weigel et al. 2006). In the Riviera Valley the asymmetric circulation was induced by the curvature of the valley, however, in our case the asymmetry in the flow pattern is rather caused by insolation and albedo differences.

The vertical transport of aerosols by slope winds reduces concentrations near the bottom of the valley, however, detrainment of aerosols from the slope wind layer causes higher aerosol concentrations at mid-valley levels (compare Figs. 5b and 6b). In Fig. 6b at least two aerosol layers can be identified which spread horizontally from the sun-exposed slope towards the valley center. A redistribution of aerosols was observed also in other studies. Chazette et al. (2005) found a multi-layered structure during winter in the Maurienne valley, where the snow coverage was only scattered, while in the fully snowcovered Chamonix valley no elevated layers of aerosols could be detected. They attributed this pattern to the more efficient mixing due to convection in the nearly snow free valley. In our case the pattern appears to be related to winds that partially separate from the slope wind layer and transport aerosols towards the center of the valley. This partial separation of winds from the slope occurs at the heights of two shallow inversion layers which are found in the profile of Fig. $4 \mathrm{c}$ at $\sim 900 \mathrm{~m} \mathrm{MSL}$ and $\sim 1250 \mathrm{~m} \mathrm{MSL}$, 

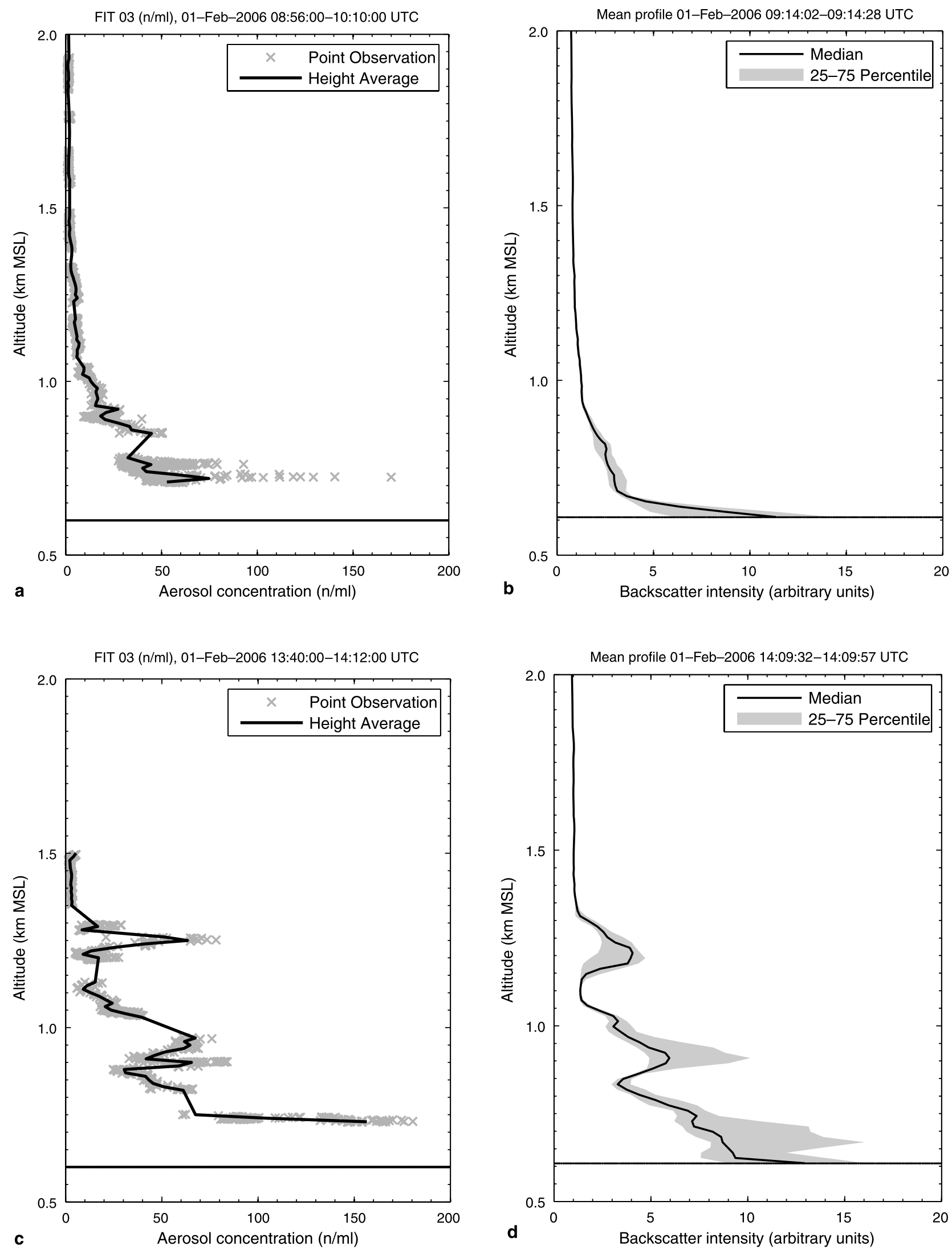

Fig. 7. Vertical profiles of (a) and (c) aerosol concentration and (b), (d), and (e) ABI constructed from a subset of data shown in Figs. 5 and 6, respectively. Only data within a 2-km wide subdomain near the valley center are used. In (a) and (c) individual point measurements within this subdomain are shown as gray marks and a height average as solid line. In (b), (d) and (e) the median is shown as solid line and the 25 and 75 percentiles as gray shaded area. (a) and (b) are valid for $\sim 09$ UTC, (c) and (d) for $\sim 14$ UTC, and (e) for $\sim 15$ UTC on 01 February 2006. See text for further explanation 


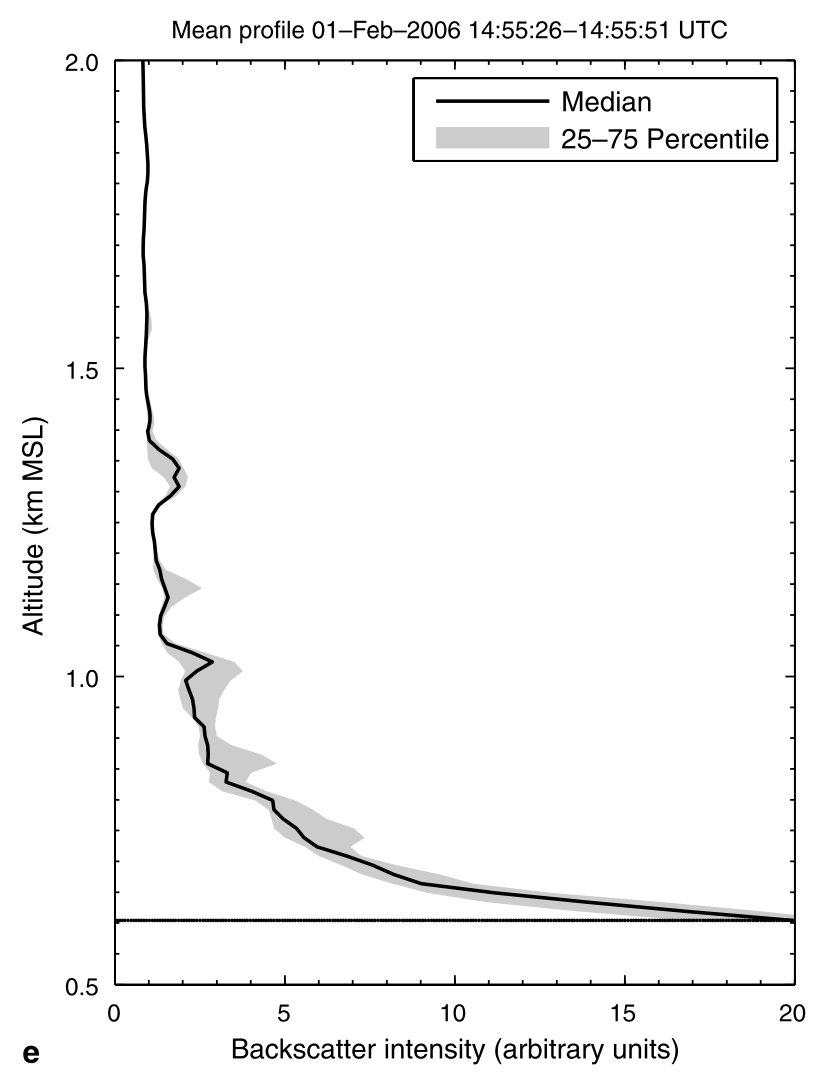

Fig. 7 (continued)

respectively. Even though the valley wind regime is dominating below $\sim 1 \mathrm{~km} \mathrm{MSL}$, some indication for a cross-valley flow component within these inversion layers is given by weak northerly winds (see Fig. 4d). A theoretical description of this phenomenon is presented in Vergeiner and Dreiseitl (1987). Their conceptual model indicates that an elevated inversion layer inhibits mass flux in the slope wind layer which favors flow splitting into two currents: a remaining reduced upslope flow and a separating flow spreading horizontally along the inversion layer. In our specific case there are at least two elevated inversion layers that correspond with two aerosol layers. A third layer may be found at $\sim 1500 \mathrm{~m}$ MSL (cf. Figs. 3a and 6b). It becomes obvious that a continuous reduction of vertical mass flux within these inversion layers hinders a complete removal of pollutants from the valley atmosphere.

The same cross section approx one hour later (not shown) indicates transport of aerosols from these layers back to the slope and down to the valley floor. It appears that this is the time when the thermal circulation weakens and starts to re- verse. With the reverse of the upslope flow into a downslope flow, the aerosols are transported back towards the valley floor. This process is also apparent when comparing the two vertical profiles in Fig. 7d and e, which are separated by approx one hour. Therefore, no effective vertical exchange of the polluted air mass takes place.

\subsection{Comparison of lidar and in-situ measurements}

In a next step a comparison of aerosol backscatter intensities (ABI) with aerosol concentrations is performed. Vertical profiles constructed from aircraft data and taken from a 2-km wide subdomain of Figs. 5 and 6, which covers the flat part of the valley between $x=-1 \mathrm{~km}$ and $+1 \mathrm{~km}$, are displayed in Fig. 7a, b for the morning flight and in Fig. $7 \mathrm{c}, \mathrm{d}$ for the afternoon flight. Figure $7 \mathrm{e}$ is the same as Fig. 7d, but approx one hour later. Figure $7 \mathrm{~b}, \mathrm{~d}$ and e shows the median of the ABI together with the 25 and 75 percentiles. The percentiles describe the variability of the backscatter signal across the valley within this $2-\mathrm{km}$ wide subdomain. The in-situ data in Fig. 7a and c show individual point measurements taken from this subdomain as well as an average computed for discrete height intervals of $10 \mathrm{~m}$. The data density of the in-situ measurements is very inhomogeneous in height. Further, the different spatial and temporal coverage of the two datasets complicates the comparison between individual point measurements of $\mathrm{ABI}$ and aerosol concentration. Despite these problems the qualitative agreement of the two systems is very good. Individual aerosol layers of high ABI and high aerosol concentration can be detected in both types of profiles. A quantitative comparison is much more difficult since no generally valid relationship can be found. Nevertheless, at least for the 01 February 2006 the ratio between the ABI and the aerosol concentration is $\sim 1 / 10$, with a strong scatter between $\sim 1 / 5$ and $\sim 1 / 15$ for individual points. Especially in the afternoon, when the aerosol distribution is very inhomogeneous in space and time, differences in the sample volume between the two instruments affect the ratio considerably.

\section{Conclusions}

Airborne aerosol observations have been collected during the wintertime in the Inn Valley. 
Measurements from an airborne aerosol backscatter lidar as well as in-situ observations have been presented. It has been shown that the spatial aerosol distribution is very much related to the thermal stratification of the valley atmosphere. A stable stratification with a strong surface inversion during the morning traps the pollutants within a shallow layer close to the ground. During the day when the stability of the valley atmosphere decreases, vertical transport of aerosols may occur. However, shallow inversion layers at midvalley levels, which may prevail throughout the day, hinder an effective vertical exchange of the polluted air mass. In our specific case thermally induced slope winds have been made responsible for the observed vertical aerosol transport. Due to differences in the snow coverage and orientation of the two valley slopes this thermal circulation was asymmetric, which resulted in an asymmetric aerosol distribution across the valley. We believe that an interaction between the slope winds and more than one elevated shallow inversion layers led to a partial separation of the upslope flow at the height of these inversion layers and caused the formation of elevated aerosol layers. Measurements of the aerosol backscatter intensity are useful for revealing a qualitative picture of the distribution of aerosols, even though the derivation of quantitative measures, such as mass density and number concentration of particulate matter is difficult.

\section{Acknowledgments}

The projects INNAP and INNOX were funded by the European Fleet for Airborne Research (EUFAR), the Tiroler Wissenschaftsfonds (TWF), and the University of Innsbruck (Nachwuchsförderung 2005 und 2006 der LFUI). ALPNAP is an EU funded project in the INTERREG IIIB Alpine Space programme. More information can be found at http:// www.eufar.net and http://www.alpnap.org. We would like to acknowledge Friedrich Obleitner and Klaus Schäfer for providing surface observations on the ALPNAP station Schwaz shown in Fig. 2 and Axel Kreuter for his support in conducting the lidar measurements.

\section{References}

Bader DC, Whiteman CD (1989) Numerical simulation of cross-valley plume dispersion during the morning transition period. J Appl Meteor 28: 652-64

Beauchamp J, Wisthaler A, Grabmer W, Neuner C, Weber A, Hansel A (2004) Short-term measurements of CO, $\mathrm{NO}, \mathrm{NO}_{2}$, organic compounds and PM10 at a motor- way location in an Austrian valley. Atmos Environ 38: 2511-22

Carnuth W, Trickl T (2000) Transport studies with the IFU three-wavelength aerosol lidar during the VOTALP Mesolcina experiment. Atmos Environ 34: 1425-34

Chazette P, Couvert P, Randriamiarisoa H, Sanak J, Bonsang B, Moral P, Berthier S, Salanave S, Toussaint F (2005) Three-dimensional survey of pollution during winter in French Alps valleys. Atmos Environ 39: 1035-47

Emeis S, Jahn C, Münkel C, Münsterer C, Schäfer K (2007) Multiple atmospheric layering and mixing-layer height in the Inn valley observed by remote sensing. Meteorol Z 16: 415-24

Furger M, Dommen J, Graber WK, Poggio L, Prévôt ASH, Emeis S, Grell G, Trickl T, Gomiscek B, Neininger B, Wotawa G (2000) The VOTALP Mesolcina valley campaign 1996 - concept, background and some highlights. Atmos Environ 34: 1395-412

Gohm A, Harnisch F, Fix A (2006) Boundary layer structure in the Inn Valley during high air pollution (INNAP). AMS, Extended abstract of the 12th Conf. on Mountain Meteorology, Santa Fe, New Mexico [http://ams.confex.com/ ams/pdfpapers/114458.pdf]

Hanna SR, Strimaitis DG (1990) Rugged terrain effects on diffusion. In: Blumen W (ed) Atmospheric processes over complex terrain. Amer Meteor Soc, pp 109-43

Heimann D, de Franceschi M, Emeis S, Lercher P, Seibert P (eds) (2007) Air pollution, traffic noise and related health effects in the alpine space - a guide for authorities and consulters. ALPNAP comprehensive report. Università degli Studi di Trento, Dipartimento di Ingegneria Civile e Ambientale, Trento, Italy, $335 \mathrm{pp}$

Meister A, Fix A, Flentje H, Wirth M, Ehret G (2003) TropOLEX: a new tuneable airborne lidar system for the measurement of tropospheric ozone. 6th Int. Symposium on Tropospheric Profiling, Leipzig, 14-20 September 2003, pp. 233-5

Neininger B, Fuchs W, Baeumle M, Volz-Thomas A, Prévôt ASH, Dommen J (2001) A small aircraft for more than just ozone: MetAir's "Dimona" after ten years of evolving development. Proc. 11th Symp. on Meteorological Observations and Instrumentation. Albuquerque, NM, USA, 14-19 January 2001, pp 123-8

Pope CA, Burnett RT, Thun MJ, Calle EE, Krewski D, Ito K, Thurston GD (2002) Lung cancer, cardiopulmonary mortality, and longterm exposure to fine particulate air pollution. J Am Med Assoc 287: 1132-41

Prévôt ASH, Dommen J, Bäumle M, Furger M (2000) Diurnal variations of volatile organic compounds and local circulation systems in an Alpine valley. Atmos Environ 34: 1413-23

Schnitzhofer R, Dunk1 J, Norman M, Wisthaler A, Gohm A, Obleitner F, Neininger B, Hansel A (2007) Vertical distribution of air pollutants in the Inn Valley atmosphere in winter 2006. ICAM 2007, Extended abstract of the 29th Int. Conf. on Alpine Meteorology, Chambery, France [http://www.cnrm.meteo.fr/ICAM2007/html/ PROCEEDINGS/ICAM2007/extended/manuscript_ 96.pdf] 
Thudium J (2003) Szenarien der Entwicklung des Schweren Güterverkehrs 2002-2012 und Auswirkungen des Nachtfahrverbotes auf der A12 Oktober 2002-Januar 2003. Technical report, Ökoscience AG, prepared by order of the Tiroler Landesregierung. Available at http://www. tirol.gv.at/themen/umwelt/luft/

Vergeiner I, Dreiseitl E (1987) Valley winds and slope winds - observations and elementary thoughts. Meteorol Atmos Phys 36: 264-86

Wakimoto RM, McElroy JL (1986) Lidar observation of elevated pollution layers over Los Angeles. J Climate Appl Meteor 25: 1583-99
Weigel AP, Chow FK, Rotach MW, Street RL, Xue M (2006) High-resolution large-eddy simulations of flow in a steep Alpine valley. Part II: Flow structure and heat budgets. J Appl Meteor Climatol 45: 87-107

Whiteman CD (2000) Mountain meteorology. Oxford University Press, Oxford, 355 pp

Wotawa G, Seibert P, Kromp-Kolb H, Hirschberg MM (2000) Verkehrsbedingte Stickoxid-Belastung im Inntal: Einfluss meteorologischer und topographischer Faktoren. Endbericht zum Projekt Nr. 6983 "Analyse der Schadstoffbelastung im Inntal" des Jubiläumsfonds der Österreichischen Nationalbank 